\title{
КОНФУЦИАНСТВО КАК ФОРМА РЕЛИГИОЗНОГО НАТУРАЛИЗМА
}

\author{
Такер М. Э.
}

Конфуцииаский религиозный натурализм включает в себя динамическую космологическую направленность, которая переплетается с духовными выражениями в форме этики коммунитаризма общества, самосоверменствования человека и ритуальных выражений, объединяющих себя, общество и космос. Это переплетение духовной интеграции, которое имело долгую и богатую историю в Китае и других странах Восточной Азии, заслужсивет более тщңательного изучения. Автор статьи полагает, что эти исследования укажут путь к будущим формам конфуцианского религиозного натурализма в новых и творческих проявлениях.

Ключевые слова: конфуциианство, религиозный натурализм, самосовершенствование, коммунитаризм, космология.

Confucianism religious naturalism encompasses a dynamic cosmological orientation that is interwoven with spiritual expressions in the form of communitarian ethics of the society, self-cultivation of the person, and ritual expressions integrating self, society, and cosmos. This tapestry of spiritual integration, which has had a long and rich history in China and in other countries of East Asia deserves further study. The author thinks such studies will also point the way toward future forms of Confucian religious naturalism in new and creative expressions.

Keywords: Confucianism, religious naturalism, self-perfection, communitarism, cosmology.

Искусство конфуцианского религиозного натурализма можно описать как открытие космологического бытия в повседневной рутине. Для конфуцианства в обычном находится необычное, светское означает священное, трансцендентное видится в имманентном. Конфуцианство отличает всеобъемлющий космологический контекст, который определяет мировоззренческую ориентацию человечества. Его нельзя назвать традицией поиска освобождения за пределами мира, это то, что утверждает духовность становления более гуманной личности в самом мире. Путь имманентности есть путь конфуцианства ${ }^{1}$.

Средства самопреобразования - это самосовершенствование по отношению к другим и природе. Оно рассматривается в связи с традицией научной мысли, воплощенной в направленности на ценность культуры и ее многочисленные прояв-

\footnotetext{
* Такер Мэри Эвелин - научный сотрудник Йельского университета, старший преподаватель богословского факультета и факультета лесохозяйственных и природоохранных исследований. Содиректор (с Джоном Гримом) Форума по религии и экологии в Йельском университете. E-mail: maryevelyn.tucker@yale.edu.

${ }^{1}$ В этой статье, кроме отмеченных случаев, мы используем термины «конфуцианский» и «конфуцианство» для обозначения традиции в широком смысле, необязательно проводя различия между ранними классическими конфуцианскими течениями и более поздними неоконфуцианскими формами в Китае, Корее и Японии.
} 
ления. Оно нацелено на развитие плодотворных общественных отношений, эффективных образовательных систем, устойчивых сельскохозяйственных моделей и гуманного политического управления в контексте динамических, жизненно важных процессов Вселенной.

Спешим добавить, что аспекты трансцендентности не полностью отсутствуют в этой традиции, например, в представлении о Небе в классическом конфуцианстве или о Высшей цели в позднем неоконфуцианстве ${ }^{2}$. Тем не менее конфуцианская духовность делает акцент на культивировании своей небесной природы по отношению к другим людям и самой Вселенной. Здесь нет стремления спастись от сансары, циклов страдания, как в индуизме или буддизме, поисков загробного спасения, как в иудаизме, христианстве или исламе. Скорее, собственный микрокосм и макрокосм Вселенной косвенно и открыто рассматриваются как аспекты единой, но постоянно меняющейся реальности.

Таким образом, сплетение воедино имманентности и трансцендентности в этой традиции создает уникальную форму духовной практики среди мировых религий. Между сверхъестественными и естественными порядками не существует онтологического раскола. Это действительно можно назвать одним из выдающихся вкладов в конфуцианство, как в исторически сложившееся, так и в его современные возрожденные формы.

Описание формы религиозного натурализма является одной из нелегких задач по ознакомлению читателя с удивительным построением конфуцианской мысли как классического, так и современного периода. Мы надеемся, что при исследовании этих отличительных форм конфуцианства само понятие религиозного натурализма будет расширяться и в итоге обогащаться. Важно понимать, что многие стремления конфуцианства не всегда были достижимы. Действительно, часто преобладали иерархические и автократические аспекты, подобно досовременным религиозным традициям.

\section{Что такое конфуцианский религиозный натурализм?}

Среди религиозных традиций мира конфуцианство отличается тем, что его понимание затруднительно с точки зрения религиозных или духовных аспектов. Отчасти сложность проблемы относительно религиозного характера конфуцианства заключается в изучении целого ряда взаимосвязанных вопросов. Главнейшим среди них является вопрос о том, как определять конфуцианство: как политическую систему, этические учения, социальные нормы, философию человека или религиозное мировоззрение ${ }^{3}$. Мы рассматриваем все эти характеристики как часть конфуцианства. Однако здесь мы стремимся к изучению конфуцианства

\footnotetext{
${ }^{2}$ Как полагает Ту Вэймин, «несмотря на трудность осмысления трансцендентности как радикального отличия, приверженность конфуцианцев к окончательному самопреобразованию обязательно включает в себя трансцендентальное измерение» [Confucian... 1985: 137]. Это не «радикальная трансцендентность, а имманентность с трансцендентным измерением» [Centrality... 1989: 121]. См. аналогичные доказательства, приведенные ранее в статье Лю Шу-хсена [Liu Shu-hsien 1972: 45-52]. Роджер Эймс и Дэвид Холл утверждали, что конфуцианская традиция, особенно в ее классических формах, практически не рассматривает трансцендентность [см.: Hall, Ames 1987; 1998; см. также: Ames 1984: 7-23].

3 Лю Шу-хсен и другие философы заметили, что конфуцианство как духовный идеал, воплощающий определенные духовные ценности и стремления, следует отличать от конфуцианства, входящего в социальные и политические идеологии и институты [см.: Tu Weiming 1996; см. также: Liu Shu-hsien 1998].
} 
необязательно в качестве «религии» как таковой, а как религиозного натурализма с духовным измерением.

Мы воздерживаемся от использования термина «религия» для описания конфуцианства, поскольку религия довольно часто ассоциируется с формальными институциональными структурами и чаще всего с особенностями западных религий, такими как теизм, личное спасение души и естественные/сверхъестественные дихотомии ${ }^{4}$. Таким образом, термин «религия» может затруднять, а не разъяснять понимание отличительных религиозных и духовных особенностей конфуцианского натурализма 5 . Поэтому вместо утверждения конфуцианства как религии (что само по себе проблематично для многих людей) мы предполагаем, что конфуцианство является религиозным натурализмом с космологической направленностью ${ }^{6}$. Этот космологический подход реализуется в отношении микрокосма «самого себя» к макрокосму Вселенной посредством духовных практик общинной этики, самопреобразования и ритуальных связей.

Религиозный натурализм в конфуцианском контексте - это то, что дает людям всеобъемлющий и определяющий ориентир на пути к решению проблем. Духовность - это то, что способствует выражению глубоких стремлений человека, связанных с этими ключевыми проблемами. Поскольку религиозное мировоззрение считается частью определенного набора культурных идеалов и практик, в которых рождается человек, духовность может рассматриваться как средство достижения этих идеалов. Конфуцианский религиозный натурализм отличается своим космологическим контекстом, в котором люди завершают триаду Неба и Земли. Конфуцианская духовность требует дисциплины и практики наряду со спонтанностью и созиданием. Конфуцианская духовность устанавливает различные этические обязательства для определенных человеческих отношений, углуб-

${ }^{4}$ Хотя можно было бы использовать некоторые западные определения религии, чтобы показать, что конфуцианство - тоже религия, эти определения могут ограничивать понимание природы конфуцианской духовности. Например, мы можем основываться на определениях религии Пауля Тиллиха и Фредерика Стренга. Для Тиллиха религия сосредотачивается на конечной цели, в то время как Стренг предполагает, что религия является средством конечного преображения [см.: Tillich 1957; Streng 1985].

Оба этих широких определения применимы к конфуцианству. Конечная цель в конфуцианстве очевидна, когда человек отзывается на волю Небес, которая открывается в божественно дарованной природе и проявляется в бренном мире. Конечное преображение в конфуцианстве включает в себя способы самосовершенствования, которые являются интеллектуальными, духовными и моральными. Его цель состоит в том, чтобы сделать человека целостной личностью, а именно - более чутким и сострадательным, насколько это возможно. Конечное преображение ведет к мудрости. Тем не менее это достижение находится в пределах чувственного восприятия мира, а не отдельно от него, и направлено на благо более крупного общества, а не только на спасение отдельного человека. Это отличает конфуцианскую религиозность от западных форм религии. [О природе религии см. также: Smith 1963.]

Определение конфуцианского мировоззрения (как с философской точки зрения, так и с религиозной), за исключением западных категорий, - главная проблема Роджера Эймса и Дэвида Холла, которые предполагают, что конфуцианство является одновременно и нетеистическим, и глубоко религиозным [см. их комментарий к «Учению о срединном и неизменном» в: Ames, Hall 2001].

${ }^{5}$ Ту Вэймин отметил: «Проблему того, является ли неоконфуцианство религией, не следует путать с более важным вопросом: что значит быть религиозным в неоконфуцианском сообществе? Ответ на первый вопрос часто зависит от конкретной интерпретирующей позиции, которую мы выбираем, чтобы понять, что составляет парадигму религии, которая может иметь мало общего с нашими знаниями о неоконфуцианстве как духовной традиции» [Tu Weiming 1985: 132].

${ }^{6}$ Мы высоко ценим работу Уильяма Теодора де Бари и Ту Вэймина в данной области. Об одном из первых всесторонних обсуждений религиозных аспектов конфуцианства можно прочитать в книге [de Bary 1975]. По данному вопросу см.: Tu Weiming 1989; Ivanhoe 2000, а также многочисленные работы Роджера Эймса и Дэвида Холла, включая последнюю книгу [Ames, Hall 2001]. 
ляет субъективизм в своих методах самосовершенствования и провозглашает единство космических и человеческих сил в своих ритуальных связях. Она направлена на то, чтобы развернуть творческое начало человека среди концентрических кругов взаимозависимого творения - от человека к Вселенной.

Одним из способов оценить своеобразие конфуцианского религиозного натурализма и его духовного выражения является изучение многообразных особенностей религий с общим географическим местом происхождения. Необходимо отметить, что Карл Ясперс назвал расцвет мировых религий, который произошел в VI в. до н. э., «осевым временем» [Jaspers 1953]. Этот период характеризуется с точки зрения трех основных центров происхождения: в Западной Азии - иудаизм, христианство, ислам; в Южной Азии - индуизм, джайнизм, буддизм; в Восточной Азии - конфуцианство и даосизм. Первую группу можно описать как пророческие и исторически сложившиеся религии, вторую можно рассматривать как мистические религии и религии освобождения, третья группа может быть представлена религиозным натурализмом космической и социальной гармонии [Berthrong 1994: 216]. Именно взаимодействие космического и социального лежит в основе духовной динамики конфуцианского натурализма.

\section{Привлекательность конфуцианского религиозного натурализма}

Дэвид Кейтли отмечает: «Сила и стойкость конфуцианской традиции, несмотря на то, что ее проявления часто носили светский характер, не могут быть объяснены в полной мере, как и ее истинная природа не может быть понята до тех пор, пока мы не рассмотрим религиозные взгляды, которые способствовали рождению этой традиции и продолжали ее поддерживать» [Keightley 1978: 117, 224]. Очевидно, что конфуцианская мысль привлекала и отдельных людей, и целые группы в Восточной Азии на протяжении веков за рамками ее политического или идеологического использования. Отдельные ученые и преподаватели занимались изучением и практикой конфуцианства для интеллектуального вдохновения, личного назидания, духовного роста и ритуального выражения. Распространение конфуцианства в Корее, Японии и Вьетнаме доказывает это. Особенно очевидным это было в Японии, где не существовало системы государственных экзаменов для продвижения по карьерной лестнице. Например, в эпоху Токугава (1603-1868 гг.) многие японские ученые и преподаватели ценили конфуцианство за его самоценность и помогали его распространению в обществе посредством создания школ [см.: Rubinger 1982].

Конфуцианство - это больше, чем традиционный стереотип модели создания общественного порядка и политической стабильности, иногда используемый в жестоких или диктаторских целях. В то время как конфуцианство стремилось создать стабильные и гармоничные общества, оно также поощряло проведение личных и общественных реформ, а также пересмотр моральных принципов и духовных практик, соответствующих различным контекстам [de Bary 1953]. Это проявляется в конфуцианской морально-политической теории начиная с ранней классической концепции исправления имен в Аналектах до четкого определения понятия права на революцию, введенного Мэн-цзы. Это также прослеживается в более поздней неоконфуцианской практике, заключающейся в том, чтобы выражать протест императору и при необходимости лишать полномочий безответственное или коррумпированное правительство. 
На личностном уровне весь процесс самосовершенствования в конфуцианской духовной практике был направлен на достижение аутентичности и искренности благодаря добросовестному изучению, критическому самоанализу, постоянным усилиям и готовности изменить себя [de Bary 1991]. Главным в этом процессе считалось «изучение себя», а не просто безапелляционное усвоение идей или попытка произвести впечатление на других [Ibid.]. Таким образом, аутентичности можно достичь только путем постоянного преобразования, чтобы самому находиться в согласии с созидательными и порождающими силами Неба и Земли $^{7}$. Эти учения стремились внедрить процесс гармонизации в соответствии с динамическими космологическими механизмами природы. Таким образом, преобразование провозглашалось как сила добра в естественном порядке и в человеческой деятельности. Этот процесс гармонизации с преобразованиями во Вселенной можно определить как главный источник конфуцианской духовности, выраженной в различных формах самосовершенствования. Это является основой конфуцианского религиозного натурализма.

Пристальное внимание к положительным аспектам преобразований прослеживается в каждом периоде конфуцианства, а также в его распространении в других географических областях. Преобразование самого себя, общества и космоса подтверждалось и отмечалось с раннего периода становления, в результате чего появилась «Книга перемен» (И-Цзин). Позже, в эпоху династии Хань, конфуцианство придавало особое значение насущным связям между человеком и различными элементами природы ${ }^{8}$. В эпоху династии Сун в XI и XII вв. неоконфуцианство подчеркивало способность Неба и Земли к созиданию. Конфуцианская духовность во всех ее разнообразных выражениях в Восточной Азии рассматривалась как мощное средство личностного преобразования. При этом она служила потенциальным инструментом установления социальной гармонии и политического порядка посредством этики коммунитаризма и ритуальной практики. В ней подчеркивалось нравственное преобразование, которое распространялось через концентрические круги, а не через внешнее навязывание законных и бюрократических ограничений. Именно этот момент отличал конфуцианские стремления и идеалы от легалистов, таких как Хань Фэй-цзы, который осознавал, что человека может ограничивать и сдерживать закон, и он может измениться, если применить наказание 9 . Конфуцианство - это традиция, которая просуществовала уже более двух с половиной тысячелетий в различных исторических, географических и культурных контекстах. Оно по-прежнему претерпевает изменения и возрождается в своих современных формах ${ }^{10}$.

\footnotetext{
${ }^{7}$ См. рассуждения Ту Вэймина об этом: Tu Weiming 1989.

${ }^{8}$ Необходимо отметить, что это упорядочение космоса и общества может проявляться как в улучшении жизни, так и в сдерживании ее развития. При использовании политической идеологии эпохи Хань данные становятся противоречивыми.

${ }^{9}$ Тем не менее конфуцианцев уличили в прагматичной политике управления, которая часто не только требовала обращения к личному нравственному преображению и ритуальной практике в качестве сдерживающих факторов, но и признавала, что закон и наказание играли свою роль, хотя и в качестве вторичной меры.

${ }^{10}$ Многие произведения западных конфуцианских ученых переводятся на китайский язык благодаря возродившемуся интересу к конфуцианству в Китае. К ним относятся работы В. Теодора де Бари, Ту Вэймина, Роджера Эймса и Дэвида Холла, Роберта Невилла, Джона Бертрона, а также двухтомный труд о конфуцианской духовности [см.: Tu Weiming, Tucker 2003].
} 


\section{Обзор исторического развития конфуцианства}

Конфуцианская традиция по-разному выражалась в Китае, Корее, Японии, Вьетнаме, Гонконге, Тайване и Сингапуре. Изучение конфуцианства как единственной традиции является проблематичным из-за его географического распространения, исторического развития и разнообразных форм - от императорского государственного конфуцианства до местного и семейного. Тем не менее в данном обзоре предпринята попытка провести различия форм конфуцианства, для того чтобы подчеркнуть аспекты его религиозного натурализма ${ }^{11}$.

Во время возникновения традиции в Китае в 1-м тыс. до н. э. она включала передачу и преобразование конфуцианства, которое происходило в разных восточноазиатских культурных и географических контекстах. Изучая причины его распространения и привлекательности, важно подчеркнуть, каким образом оно взаимодействовало с национальными традициями в Китае и во всей Восточной Азии. Например, конфуцианство откликнулось на идеи даосизма и буддизма в Китае, шаманизма в Корее и синтоизма в Японии и смешалось с ними ${ }^{12}$. Необходимо подчеркнуть заимствование и творческое взаимодействие между различными религиозными традициями в Восточной Азии. Действительно, следует отметить так называемое единство и синкретизм трех традиций - конфуцианства, даосизма и буддизма в Китае. Это было особенно заметно в эпоху династий Мин (1368-1644) и Цин (1644-1911) [см.: Berling 1980].

Признавая это динамичное скрещивание религиозных традиций в Восточной Азии, можно также выделить четыре основных периода конфуцианской мысли и практики с исторической точки зрения. Первым этапом в Китае является классическое конфуцианство, который охватывает период примерно с VI до II в. до н. э. Это время расцвета ранних конфуцианских мыслителей, а именно - Конфуция и Мэн-цзы. Второй этап - это конфуцианство эпохи Хань, когда классическая традиция трансформировалась в политическую ортодоксальность в период Ханьской империи (202 г. до н. э. - 220 г. н. э.) и начала распространяться в других частях Восточной Азии. В это время стала развиваться теория тождества микрокосма человеческого мира с макрокосмом мира природы. Третий важный этап неоконфуцианская эпоха, которая длилась с XI до начала XX в. Она включает в себя всесторонний синтез Чжу Си в XI в. и выдающийся вклад Ван Янмина в XV и XVI вв. Влияние конфуцианства как образовательной и философской системы в этот период ощущалось во многих частях Восточной Азии. Последний этап - это новое конфуцианство ХХ в., которое представляет собой возрождение традиции под влиянием ученых, прибывших в Тайвань и Гонконг в начале правления Мао в 1949 г. ${ }^{13}$ Четыре десятилетия спустя, в октябре 1989 г., Международ-

${ }^{11}$ Очевидно, здесь существуют трудности относительно признания исторической специфики конфуцианства наряду с определением некоторых основных религиозных элементов в традиции.

12 Например, в XVII в. в Японии существовало конфуцианство в сочетании с синтоизмом, затем в XVIII в. конфуцианство отделилось от синтоизма под влиянием нативистов и снова воссоединилось с ним в конце XIX в. Японское конфуцианство как мировоззрение и как форма духовного совершенствования попрежнему является частью многих новых религий в Японии и заслуживает последующего изучения [см.: Hardacre 1986].

${ }^{13}$ Ту Вэймин заявляет о новом конфуцианстве как о «третьей эпохе конфуцианского гуманизма» после классического и неоконфуцианского периодов [см.: Confucianism... 1986: 3-21]. Джон Бертрон выделяет шесть периодов конфуцианства, которые включают Хань, Тан и, позднее, доказательное учение Цинь [см.: Berthrong 1994: 77-83, 191-192]. 
ное конфуцианское общество провело две крупные конференции в Пекине и Цюйфу, на родине Конфуция, чтобы исследовать будущее конфуцианского пути. Эти конференции были предназначены для празднования 2540-летия со дня рождения Конфуция, и обе они означали интерес конфуцианских практиков к будущему.

\section{Мировоззрение и мораль: органическая космология и этика коммунитаризма}

Конфуцианскому религиозному натурализму, несмотря на то что он не является единственным и единообразным, присуща органическая космология [Needham 1956: 291-293], характеризующаяся «непрерывностью бытия» [см.: Tu Weiming 1985] внутри «имманентного космоса» ${ }^{14}$. Между трансцендентным, сверхъестественным порядком и имманентной, мирской ориентацией не существует четкого разделения, как в западных религиях. «Учение о срединном и неизменном (Чжун юн)» гласит: «Путь Неба и Земли можно описать в одном предложении: они не двойственны по природе, поэтому они создают мир неведомым образом. Путь Неба и Земли обширен, глубок, высок, блистателен, бесконечен и продолжителен» ${ }^{15}$.

Осознание безупречного взаимодействия людей с Вселенной возникает без онтологического разрыва между нашим и другим миром. Конфуцианское космологическое мировоззрение - это мировоззрение, которое охватывает изменчивую и динамичную непрерывность бытия. С точки зрения морали или этики это предполагает развитие глубоких взаимосвязей Неба, Земли и людей. Это глубокое символическое выражение троичного взаимодействия имманентного космоса неоднократно упоминается как в конфуцианских, так и в неоконфуцианских текстах, цитируемых в Восточной Азии ${ }^{16}$. Как отмечает Ту Вэймин, эта космология является не теоцентрической, не антропоцентрической, а скорее антропокосмической. В этом смысле акцент делается не только на божественном и человеческом, как и в преобладающей модели на Западе. Всестороннее взаимодействие Неба, Земли и людей, скорее, даже подчеркивается термином «антропокосмический» [Tu Weiming 1989: 102-107]. Таким образом, мировоззрение органической космологии создает контекст сложной коммунитарной модели социальной этики, которая отличает восточноазиатские общества.

Взаимное притяжение вещей друг к другу как в человеческом мире, так и в мире природы порождает внутреннюю этическую систему взаимных отношений. Инстинктивные качества человеческого сердца, такие как способность к состраданию и сопереживанию, воспитываются и выражаются в человеческих отношениях и обрядах (Мэн-цзы 2А: 6). Человек не является изолированным индивидуумом, нуждающимся в освобождении личным Богом, но он глубоко погружен

\footnotetext{
14 Этот термин используют Роджер Эймс и Дэвид Холл в своей книге [Hall, Ames 1987: 12-17].

${ }^{15}$ Перевод: Wing-tsit Chan 1963: 109.

${ }^{16}$ Наряду с другими они включают следующие работы: «Книга перемен» (приложение третье), «Книга ритуала» (глава 7), «Учение о срединном и неизменном» (глава 22), «Драгоценные жемчужины летописи “Весна и осень”» Дун Чжуншу (глава 44), «План Великого предела» Чжоу Дуньи, «Западная надпись» Чжан Цзай, «Второстепенные пояснения к древнему тексту Великого учения» Ван Янмина [см.: Bary, Bloom 1999].
} 
в совокупность животворящих и жизнеобеспечивающих отношений и обычаев. В пределах этой органической вселенной человек рассматривается как микрокосм макрокосма, где его действия влияют на большое целое, подобно ряби на пруду, выраженной в Великом учении. Таким образом, существует относительный резонанс личного и космического общения, вызываемый аутентичностью (чэн), как показано в «Учении о срединном и неизменном» ${ }^{17}$. Человек тесно связан с различными сообществами через обычаи, от естественной привязанности к семье до общественно-политического порядка и символического сообщества Неба и Земли $^{18}$. Люди достигают полной идентичности, будучи членами великой триады «Небо - Человек - Земля». Внутри этой триады Небо является ведущей нравственной составляющей, Земля - жизненно важной моральной силой, а люди соавторами гуманного и морального общественно-политического порядка.

\section{Космология и развитие: Созидательное творчество Небес и преображение людей}

Конфуцианский религиозный натурализм охватывает обширный космологический порядок, который отличается созидательным творчеством Небес как животворящей силы, которая непрерывно поддерживается сама собой ${ }^{19}$. Подобно процессу Уайтхеда, Вселенная в конфуцианстве рассматривается как разворачивающийся творческий процесс, а не как статическая инертная механическая система, контролируемая отсутствующим или удаленным божеством [см.: Berthrong 1994]. В качестве защищающей, поддерживающей и преобразующей силы Небо помогает привести все процессы к их естественному, космологическому завершению. Это происходит потому, что люди тесно связаны с небесной природой, которая позволяет им преображаться с помощью самосовершенствования ${ }^{20}$.

Таким образом, идеал созидательной космологии поддерживает образование, обучение и самопреобразование. Оптимистическая точка зрения о том, что человек наделен божественной природой, проявляется в конфуцианском этосе образования и семьи, который теоретически создает систему ценностей, способствующую воспитанию врожденной человеческой доброты и креативному преобразованию личностного потенциала. Данный этос вызывает сыновье чувство долга по отношению к Небесам за то, что они даровали жизнь, и за божественно дарованную природу. Постоянное моральное совершенствование с целью улучшения самого себя и общества является способом отблагодарить Небеса. Символом или моделью, объединяющими этот аспект мировоззрения и этос, является благородный человек (цзюн-цзы) или мудрец (шэн), который «слышит» волю Небес и способен естественным образом воплотить ее в процессе обучения и самосовершенствования. Таким образом, мудрец является наивысшим воплощением духовных стремлений конфуцианской традиции [Taylor 1990].

\footnotetext{
${ }^{17}$ См. главы 22, 25, 26 «Учения о срединном и неизменном» [Bary, Bloom 1999].

${ }^{18}$ См. статью Томаса Берри в первом томе [Berry 2003].

19 «Книга перемен», приложение НІ 2:1/8. См. также главу “Creative Principle” в [Hellmut 1977]. Неоконфуцианцы часто ссылаются на продуктивные и репродуктивные силы Вселенной (Ch. sheng sheng, Jp. sei sei).

${ }^{20}$ См. главу 1 «Учения о срединном и неизменном» [Bary, Bloom 1999].
} 


\section{Жизненная сила Земли и совместное творчество людей: космологические связи и человеческий обычай}

Созидательная способность Небес в конфуцианском космологическом мировоззрении сопровождается жизненной силой мира природы. Ощущение жизненной силы природы наполняет многие конфуцианские тексты, начиная с раннего текста «Книги перемен» (И-Цзин) до неоконфуцианской переоценки этого текста [см.: Smith et al. 1990]. Эта жизненная сила понимается как часть сезонных циклов природы, а не как развивающаяся эволюционирующая Вселенная, обсуждаемая современными философами и теологами. Она выражается в тщательно продуманной серии связей (сезонных, направленных, элементарных), которые рассматривались в ханьском конфуцианстве в качестве моделей, предполагающих тщательное регулирование, необходимое в социальной и политической сферах [см.: Rosemont 1984; Queen 1996; Eno 1990; Henderson 1984]. Этот космологический взгляд на интегральные циклы природы усиливает этос данными процессами благодаря созданию гармоничного общества и управления с соответствующими ритуальными структурами. Обряды отражают шаблонные структуры мира природы и связывают людей друг с другом, с миром предков и с космосом в целом.

Жизненная сила (Ци) Вселенной - это то, что объединяет людей и природу, связывая их мировоззрение и дух, и дает людям возможность стать сотворцами вместе со Вселенной ${ }^{21}$. Как отмечает Мэн-цзы, именно Ци объединяет Правоту (этос) и Путь (мировоззрение), заполняя все пространство между Небом и Землей ${ }^{22}$. Таким образом, моральный императив конфуцианства заключается в том, чтобы осуществить соответствующий этический и ритуальный выбор, связанный с созидательными силами Пути, и тем самым способствовать улучшению социального и политического порядка.

Конфуцианский религиозный натурализм провозглашает изменения, поскольку они проявляются в созидательном творчестве Неба и в жизнеспособности Земли. В частности, разнообразные и динамические модели космологических изменений отмечаются как часть животворящей Вселенной. Обряды и музыка предназначены для создания гармонии с космическими изменениями и для содействия процессу личностного преобразования. Обряды способствуют объединению мировоззрения о космических изменениях с этосом человеческих изменений в обществе, тем самым гармонизируя естественный и человеческий порядок. Обряды и музыка - это средства создания благодати, красоты и согласия. Таким образом, природные космологические структуры Земли выступают противовесом в этосе социальных моделей, выраженных в ритуальном поведении и музыке. С точки зрения космологии гармония со Вселенной уравновешивается духом взаимного резонанса человеческих отношений и выражается в закономерном ритуальном поведении.

\section{Вывод}

Конфуцианский религиозный натурализм включает в себя динамическую космологическую направленность, которая переплетается с духовными выражениями в форме этики коммунитаризма общества, самосовершенствования челове-

\footnotetext{
${ }^{21}$ См. использование Ту Вэймином термина «сотворец» в: Commonality... 1989: 70, 78, 98, $102,106$.

${ }^{22}$ Мэн-цзы 2А: 2.
} 
ка и ритуальных выражений, объединяющих себя, общество и космос. Это переплетение духовной интеграции, которое имело долгую и богатую историю в Китае и других странах Восточной Азии, заслуживает дальнейшего изучения. Мы полагаем, что такие исследования также укажут путь к будущим формам конфуцианского религиозного натурализма в новых и творческих проявлениях.

Перевод с английского

Н. С. Дорофеевой, Е. С. Столяровой

\section{Лuтература}

Ames R. T. Religiousness in Classical Confucianism: A Comparative Analysis // Asian Culture Quarterly. 1984. Vol. 12. No. 2. Pp. 7-23.

Ames P. T., Hall D. L. Focusing the Familiar. Albany, NY : State University of New York, 2001.

Bary T., Bloom I. The Sources of Chinese Tradition. New York : Columbia University Press, 1999.

Bary de W. T. A Reappraisal of Neo-Confucianisrn // Studies in Chinese Thought. The American Anthropological Association. 1953. Vol. 55. No. 5. Part 2. Memoir No. 75 (December).

Bary de W. T. The Untolding of Neo-Confucianism. New York : Columbia University Press, 1975.

Bary de W. T. Learning for One's Self. New York : Columbia University Press, 1991.

Berling J. The Syncretic Religion of Lin Chao-en. New York : Columbia University Press, 1980.

Berthrong J. All Under Heaven: Transforming Paradigms in Confucian-Christian Dialogue. Albany, NY : State University of New York, 1994.

Berry T. 2003. Affectivity in Classical Confucian Tradition // Confucian Spirituality. Vol. 1 / Ed. by Tu Weiming, M. E. Tucker. New York : Crossroad Publishing Company. Pp. 96-112.

Centrality and Commonality: An Essay on Confucian Religiousness. Albany, NY : State University of New York, 1989.

Commonality and Centrality. Albany, NY : State University of New York, 1989.

Confucian Thought: Selfhood as Creative Transformation. Albany, NY : State University of New York, 1985.

Confucianism: The Dynamics of Tradition / Ed. by I. Eber. New York : Macmillan, 1986.

Eno R. The Confucian Creation of Heaven. Albany, NY : State University of New York, 1990.

Hall D. L., Ames R. T. Thinking Through Confucius. Albany, NY : State University of New York, 1987.

Hall D. L., Ames R. T. Thinking From the Han: Self, Truth and Transcendence in Chinese and Western Culture. Albany, NY : State University of New York, 1998.

Hardacre H. The World View of the New Religion // Kurozumikyo and the New Religions of Japan / Ed. by P. Hardacre. Princeton : Princeton University Press, 1986. 
Hellmut W. Heaven, Earth and Man in the Book of Changes. Seattle : University of Washington Press, 1977.

Henderson J. The Development and Decline of Chinese Cosmology. New York : Columbia University Press, 1984.

Ivanhoe P. J. Confucian Moral Self Cultivation. Indianapolis : Hackett, 2000.

Jaspers K. Origin and Goal of History. London : Routledge \& K. Paul, 1953.

Keightley D. The Religious Commitment: Shang Theology and the Genesis of Chinese Political Culture // History of Religions. 1978. No. 17. Pp. 211-224.

Liu Shu-hsien. The Confucian Approach to the Problem of Transcendence and Immanence // Philosophy East and West. 1972. Vol. 22. No. 1. Pp. 45-52.

Liu Shu-hsien. Understanding Confucian Philosophy: Classical and Sung-Ming. Westport, CI : Praeger, 1998.

Needham J. Civilization in China. Vol. 2. Cambridge : Cambridge University Press, 1956.

Queen S. From Chronicle to Canon: The Hermeneutics of the Spring and Autumn According to Tung Chung-shu. New York : Cambridge University Press, 1996.

Rosemont H. (Ed.). Explorations in Early Chinese Cosmology. Chico, CA : Scholars Press, 1984.

Rubinger R. Private Academies of Tokugawa Japan. Princeton : Princeton University Press, 1982.

Smith W. C. The Meaning and End of Religion. New York : Macmillan, 1963.

Smith K., Bol P., Adler J., Wyatt D. J. Sung Dynasty Uses of the I Ching. Princeton : Princeton University Press, 1990. 1985.

Streng F. Understanding Religious Life. Belmont, CA : Wadsworth Publishing Co,

Taylor R. The Religious Dimensions of Confucianism. Albany, NY : State University of New York, 1990.

Tillich P. The Dynamics of Faith. New York : Harper and Row, 1957.

Tu Weiming. Confucian Thought: Selfhood as Creative Transformation. Albany, NY : State University of New York, 1985.

Tu Weiming. Centrality and Commonality: An Essay on Confucian Religiousness. Albany, NY : State University of New York, 1989.

Tu Weiming. Confucian Traditions in East Asian Modernity: Moral Education and Economic Culture in Japan and the Four Mini Dragons. Cambridge, MA : Harvard University Press, 1996.

Tu Weiming, Tucker M. E. (Eds.). Confucian Spirituality. 2 vols. New York : Crossroad Publishing Company, 2003.

Wing-tsit Chan. A Source Book in Chinese Philosophy. Princeton : Princeton University Press, 1963. 